\title{
PHILOSOPHY AND DIGITAL HUMANITIES IN SLOVAKIA - PROBLEM OF DIGITAL TEXTUAL RESOURCES
}

The main aim of the article is to bring together free available digital textual resources of Slovak philosophy into the comprehensive list that will serve as a basis for a more systematic building of databases of resources in the future. Firstly, it consists of mapping and describing of accessible Slovak philosophical digital resources. Secondly, it illustrates methodological benefits of digital resources in digital scholarship in philosophy. The purpose of contribution is to draw attention to systematic building-up of digital textual resources in Slovak philosophy and to demonstrate the importance of the application of advanced computational processes to digital textual resources in Slovak philosophy for the purpose of digital as well as traditional armchair philosophical research.

Keywords: digital resources, bibliography, Slovak philosophy, digital humanities, philosophical methodology, digital research

\section{Introduction}

In his interview to Czech internet magazine E15, Josef Slerka (head of New Media Studies at Faculty of Arts, Charles University in Prague) explicitly said that for philosophers it would be beneficial if they learned to program the software and for technicians it would be equally beneficial if they took exam in Latin [1]. Behind this statement, despite its provocative tone, is a well-founded effort to outline the radical methodological shift that is taking place in humanities in the last decade Slerka is talking about the so-called digital humanities. In general, digital humanities is considered as a contemporary trend and methodological practices in humanities aimed at application of computational tools and digital resources for the purpose of enhancing traditional research methods and outputs in humanities as well as creating digital scholarship and active community [2]. By definition, digital humanities is a set of divergent methodological practices in scientific research realized at universities departments, centers, and labs, and applied across all humanities including philosophy (the most widespread applications can be found in linguistics, literary studies, history, media studies, anthropology). Unfortunately, in the context of Slovakia, Slerka's statement should be understood rather as a request or wish to conduct digital humanities as such and in our case particularly in philosophy (digital humanities community is active mainly in the USA, UK, and Germany, but still not based in Slovakia).

\section{Methodological objectives and purposes}

In view of Slerka's statement, the objective of the article is not to analyze the relationship of digital humanities and philosophical research in Slovakia, but to demonstrate why there is a significant absence of digital research among Slovak philosophers. We assume that besides the lack of interest in digital technology or indifference of Slovak philosophers towards digital humanities the main reason is the lack of systematical building-up and production of standardized digital resources (mainly in text format) in the Slovak language. Consequently, the main aim of the article is to examine the state and condition of accessible Slovak philosophical digital textual resource, then to methodologically and technically assess them and finally, to draw attention to a possibility of more productive and efficient utilization of digital textual resources in Slovak philosophical community. The primary purpose of the article is to bring together the majority of free available digital textual resources of Slovak philosophy into the comprehensive list that will serve as a basis for the more systematic building-up of respective databases in the future. The plan for the future is not to create a database of philosophical production in Slovakia just in the sense of periodically updated bibliography. It represents only an initial and inevitable phase of preparing the raw digital resources for the needs of digital research in terms of digital humanities. When it comes to "doing" digital humanities in philosophy (not just "talking about"), it is strategically necessary to create, manage and preserve

\footnotetext{
* Andrej Gogora

Department of General and Applied Ethics, Faculty of Arts, Constantine the Philosopher University, Nitra, Slovakia

E-mail: agogora@ukf.sk
} 
digital data suitable for philosophical digital research (i.e., for reasonable and effective application of advanced computational processes). In common sense, digital research is not possible without digital resources. So, the secondary purpose of the article is to demonstrate the importance of professional building-up, developing an online accessing of Slovak digital resources for digital as well as traditional armchair research in philosophy.

\section{Mapping of textual digital resources in Slovak philosophy}

In this section, we are going to briefly map and technically describe the most significant and well-known textual digital resources in Slovak philosophy. The criteria for including items into the list are professional philosophical production, open access or free availability on the Internet and effective applicability of respective textual data for further digital research. With respect to the nature of philosophical production, we have focused on textual resources of various types including bibliographic and scientometrics textual data. We have categorized examples in accordance with the type of original source and respective data set into the three basic groups.

\subsection{Journals, conference proceedings and monographs}

In terms of professional high-quality of published articles and quantity of freely available texts, the most important resource in Slovak philosophy is a huge online archive of international peerreviewed journal Filozofia published by Institute of Philosophy at Slovak Academy of Sciences and indexed in recognized databases such as Current Contents/Arts\&Humanities and SCOPUS. The online archive of Filozofia [3] consists at present time of 16 volumes (2000-2016) each of ten numbers and approximately six papers for each number and also numerous reflections, interviews, and reviews (moreover, five extensive supplements are available). Each text comprises of publication details such as abstract, keywords, library metadata files and digital text converted into high-quality portable document format (older ones in image low-quality). Unfortunately, the online archive does not contain either digital texts of older volumes (from 1968 to 2000) nor bibliographic references in digital form (although they are available in indexed databases) and is not equipped with advanced search options or basic scientometrics analysis. The main advantage of the archive remains the free availability of a large number of Slovak high-quality academic articles from a wide range of philosophical areas and related disciplines.

Organon $F$ is a second peer-reviewed international journal published by Institute of Philosophy and is aimed at analytic philosophy, philosophy of language, philosophy of mind, philosophy of science and philosophical logic. The online archive of Organon F [4] consists of 23 volumes (1994-2016) each of four numbers and approximately six articles for each number and also numerous interviews and reviews (moreover, 19 extensive supplements are available). Archive of Organon F broadly meets the same professional quality and technical specifications as Filozofia - the advantage is the availability of large volumes of high-quality text, the imperfection is the lack of advanced search and weak data processing.

Human Affairs: Postdisciplinary Humanities \& Social Sciences Quarterly is an international journal concerning a whole range of contemporary human and social issues. Its archive [5] is based on hybrid open access at De Gruyter, so some articles are fully accessible (in .pdf), and others have paid access. From a technical point of view, Human Affairs has, using De Gruyter technical solution, advanced search option, and data processing including hyperlinks to references and related contents. Philosophica Critica is a young international scientific, philosophical journal published twice a year at Department of Philosophy at Constantine the Philosopher University in Nitra - online archive [6] consists of five numbers with free available full-text articles. Kritika \& Kontext is another interdisciplinary journal focused on critical thinking and liberal discussion in humanities and social sciences. Online archive [7] consists of 34 numbers (1996-2012) with full accessible articles mostly in simple non-converted portable document format in image quality. Despite many technological disadvantages the journal's content mostly reflects the most current trends in philosophical discourse. Scientific journal Ostium: an openaccess journal for humanities [8] comprises of philosophical articles in simple text format so in comparison with previous journals this one provides the best quality of datasets for further computational processing. Studia Philosophica Kantiana is an international scientific journal devoted to Immanuel Kant and his philosophical legacy that is published by Institute of Philosophy at The University of Presov - online archive [9] consists of 11 free available numbers with high-quality text portable document format with no possibility of searching. Selected articles and lists of references engaged in feminist philosophy are freely available at the website of Centre for Gender Studies [10].

Conference proceedings are a relatively frequent digital textual resource in Slovak philosophy. The most significant and regularly published are conference proceedings of Slovak Philosophical Association - in the archive [11] are freely available 13 conference proceedings (1998-2015) in textual portable document format. These are a comprehensive representation of scientific contributions at the most attended Slovak philosophical conference. Institute of Philosophy also provides three free available conference proceedings of Young Philosophy conference designed for doctoral students [12]. Another conference proceedings are available on the websites of various departments - Department of Philosophy at Constantine the Philosopher University in Nitra provides ten numbers of scientific text-book Philosophica [13]; Department of Philosophy at University of 
Matej Bel also makes a few conference proceedings public in portable document format [14]. Department of Philosophy at Trnava University has released a huge collection of 45 relevant text-books [15] for students in the field of cognitive science, epistemology, philosophy of mind and methodology of science.

Some digital philosophical monographs are stored at Slovak National Corpus at L. Stur Institute of Linguistics at Slovak Academy of Sciences. However, these resources are internally processed for the purposes of computational linguistics (building-up of annotated specialized humanities subcorpus) and are not freely available for the public access [16]. In addition, it is not a secret that you can easily and illegally download a huge amount of Slovak digital philosophical resources at various web servers.

\subsection{Encyclopedias and other internet resources}

Besides articles, conference proceedings we can find digital resources in the form of internet encyclopedias, dictionaries of terms and other types of datasets. FILIT is the oldest philosophical encyclopedia [17] in Slovak maintained by professional philosopher Jozef Piacek and software engineer Milos Kravcik since 1990. FILIT is a system of philosophical entries interconnected by hyperlinks created to support the study of philosophy. Nowadays, there is no information about the exact number of entries. However, given the fact that the content of FILIT has become a part of Slovak Wikipedia at the end of the nineties, we can assume that the number may be around several thousand. Continuation of FILIT represents another project of Piacek called Auxiliary Dictionary for Philosopher (PSF) that is created as a computer program with updated databases of entries from FILIT. PSF is a result of systematic long-term endeavor to build-up digital encyclopedic resource in philosophy; and moreover, Piacek's projects FILIT and PSF can be regarded as a pioneering effort to apply computational methods in Slovak philosophy, or more precisely, they are the first examples of digital humanities in philosophy in Slovakia: "PSF is not only a tool for the study of philosophy, but it is a computer support of meta-philosophical exploration of philosophy; it is a computerimplemented model of philosophy and a tool of meta-philosophy" [18]. However, his approach lacks methodical exactness and standardized techniques: "The creation of PSF is rather part of the computer-aided philosophical meditation and imagination project, hence has a heuristic function, a function supporting exploration of new facts and new contexts rather than serving as a guide for the standard" [18]. Following FILIT and PSF we have to mention a number of Slovak Wikipedia entries under the category of philosophy - these resources together form a huge data set which has an advantage of free access and converted text format that can be very helpful for the further structuring of data and their effective applicability in computational procedures.
Another supplementary internet resources of Slovak philosophy is Gender Terminology Glossary [19] published by ASPEKT which consists of a comprehensive list of entries aimed at feminist philosophy with hyperlinks and resources provided. Terminology Portal is a project developed at Slovak National Corpus at L. Stur Institute of Linguistics [20] which contains approximately 200 terminological entries in the category of philosophy (the project is still in progress, so the number of entries will increase in the near future).

\subsection{Bibliography and scientometrics data}

Secondary but certainly no less important digital resources for the purpose of investigation of Slovak philosophical discourse regarding digital humanities are bibliographic and scientometrics data. These data provide auxiliary information on scientific practice and in combination with previous primary textual resources represent the powerful data bank for computational analysis of Slovak philosophical discourse in synchronic or diachronic viewpoints. Unfortunately, we do not have any systematically built-up and periodically up-dated bibliography of publishing activity in Slovak philosophy - we are convinced that this is one of the most recent challenges in setting up digital humanities in Slovak philosophy. Obviously, the best way to obtain bibliographic data about Slovak philosophers is to use available databases such as Web of Science, Scopus, EBSCO, Google Scholar and PhilPapers. These databases are mainly for indexed articles, in the case of non-indexed and other philosophical texts, we can utilize advanced search of the Slovak electronic library catalogues (mainly at the Slovak National Library), publishing activities statistics and special bibliographies [21]. Bibliography on the History of Philosophical Thinking in Slovakia until 1965 is a short digital online list of bibliography of works in the history of philosophy in Slovakia [22]. Electronic Glossary of Slovak Philosophers [23] consists of 39 profiles of contemporary Slovak philosophers with detailed biographic and bibliographic data, affiliations and professional focus. Finally, we can conclude that systematically building-up and online releasing of digital catalogues and bibliographies of Slovak philosophy would greatly help researchers regardless of the digital humanities objective.

Another data useful for some specific meta-philosophical and scientometrics research consists of a list of organized philosophical events, lectures, conferences and workshops in Slovakia, activity reports of philosophical departments, institutes and centers, minutes from general meetings of philosophical associations and so on. Nowadays, we should take into account that data extracted from public profiles of philosophical institutions or personal profiles of philosophers on large volumes on social networks such as Facebook and Twitter would also be very helpful for broader discursive analysis of philosophical ecosystem in Slovakia. 


\section{The future of digital research in philosophy?}

On the basis of these examples and assessment of their technical specifications, we can conclude that although we have a relatively large number of digital textual resources in Slovak philosophy, we have a lack of such advanced resources that are immediately prepared for computational analysis in the sense of digital humanities practices. In strict sense of the word, we do not have many resources that are fully applicable to digital philosophical research that meets the strict conditions of computational procedures (such as appropriate format and encoding, convertibility, representativeness and balance, faultlessness, standard of metadata assignment, annotation and tagging process, systematic data structure, digital curation standards, maintenance, long-term preservation and so on). However, it is even worse that except for the standardized processing of corpora textual resources in Slovak National Corpus we do not have many resources that are fully applicable to digital research in humanities as such.

This fundamental deficiency urgently raises the challenge to process digital textual resources in Slovak philosophy in a more systematic and standardized way. Beyond the scope of the aims of this article we would like to briefly propose some preliminary recommendations how to establish a strategy for building-up applicable digital resources in philosophy:

- To create and permanently maintain a digital database of Slovak philosophical bibliography.

- To create and permanently maintain digitization register of Slovak philosophy.

- To digitize and process in a standardized way missing resources of Slovak philosophy.

- To complete the missing conversion of digitize files into text format (UTF-8 coding).

- To complete the missing metadata assignment according to accepted standards.

- To dynamically categorize digital resources according to the accepted subject catalogue.

- To build-up a database and create an advanced search of collected digital resources.
- To prepare online user interface and to ensure open-access of digital resources.

- To resolve copyright and legal issues of freely available digital resources.

- To prepare and organize lectures and workshops on digitizing and computer processing.

We are convinced that implementation of this strategy into practice (through project activities of some digital humanities center and affiliated collaborators at Slovak philosophical departments) would successfully accomplish effective systematization and dissemination of philosophical resources, and moreover, effective application of computational statistical processes on these datasets that would in conjunction with traditional philosophical inquiry lead to valuable analyses of the Slovak philosophical discourse.

\section{Conclusion}

In conclusion, we have successfully mapped Slovak philosophical digital textual resources and created a preliminary list that is a sufficient basis for further building-up of a systematic database of these resources in the future. The content of the article maybe seems to be very technical and trivial. However, it is the fact that there is no available comprehensive list of digital textual philosophical resources in Slovak like this one. Moreover, we are convinced that, converted into database format, this list will play an important role in the further application of digital humanities in Slovak philosophy, thus in the enhancement of digital as well as traditional armchair philosophical research.

\section{Acknowledgment}

The paper is part of a grant project realized at the Constantine the Philosopher University in Nitra, Slovakia: UGA II/4/2016 . Digital humanities and philosophy, 01/2016 - 12/2017.

\section{References}

[1] Online. Available: http://student.e15.cz/q-a/filozofum-by-neuskodilo-umet-programovat-technikum-pak-zkouska-z-latiny-rikajosef-slerka-1242256.

[2] GIBBS, F.: Digital Humanities Definitions by Type. Defining Digital Humanities: A Reader. TERRAS, M., NYHAN, J. VANHOUTTE, E. (Eds.), Ashgate Publishing Company, Burlington, USA, 289-297, 2013.

[3] Online. Available: http://www.klemens.sav.sk/fiusav/filozofia/?q=sk/browse/actual/volume.

[4] Online. Available: http://www.klemens.sav.sk/fiusav/organon/?q=sk/browse/actual/volume

[5] Online. Available: http://www.humanaffairs.sk/?page_id=9.

[6] Online. Available: http://philosophicacritica.ukf.sk/full-texts.html. 


\section{kOMNIKCCle}

[7] Online. Available: http://kritika.sk/\#document(front_page).

[8] Online. Available: http://www.ostium.sk/sk/archiv/.

[9] Online. Available at: http://www.unipo.sk/filozoficka-fakulta/instituty-fakultyifi/spk/cspk/.

[10] Online. Available: https://fphil.uniba.sk/katedry-a-odborne-pracoviska/odborne-centra/centrum-rodovych-studii/publikacie/.

[11] Online. Available: http://www.sfz.sk/?q=content/zborniky-z-konferencii-sfz.

[12] Online. Available: http://www.klemens.sav.sk/fiusav/?q=sk/youngphilosophy.

[13] Online. Available: http://www.katedrafilozofieffukf.com/archiacutev.html.

[14] Online. Available: http://www.ff.umb.sk/katedry/katedra-filozofie/veda-a-vyskum/publikacie/?motherID=702.

[15] Online. Available: http://filozofia.truni.sk/ucebne-texty-690/690.htm.

[16] DEBNAR, M.: The Semantic Fields of Selected Ethical Terms in the Written and Web Subcorpus of the Slovak National Corpus. Communications - Scientific Letters of the University of Zilina, 19(1), 86-90, 2017.

[17] Online. Available: http://dai.fmph.uniba.sk/ ${ }^{\sim}$ filit/fil/fil.html.

[18] Online. Available: http://pomslovfil.yolasite.com/slovo-o-psf.php.

[19] Online. Available: http://glosar.aspekt.sk/default.aspx?ami=1\&smi=1\&vid=176.

[20] Online. Available: https://terminologickyportal.sk/index.html.

[21] KRALIK, R., PAVLIKOVA, M.: The Reception of Kierkegaard's Work in Slovakia (in Slovak). Filozofia, 68(1), 82-88, 2013; KRALIK, R.: The Reception of Soren Kierkegaard in Czech Language (in Czech). Filosoficky casopis, 61(3), 443-351, 2013.

[22] Online. Available: http://www.filozofia.sk/bib-1965.htm.

[23] Online. Available: http://www.filozofia.sk/essf.htm. 